\title{
COLOR STABILITY AND MICROSTRUCTURE CHANGES OF TWO PRESSABLE CERAMICS AFTER REPEATED FIRING PROTOCOLS
}

\author{
Zeinab N. Emam* and Shereen M. El Sayed*
}

\begin{abstract}
Statement of the problem: it is important that researchers gather more information regarding the effect of repeated firing on optical properties and microstructure of all ceramic restoration

Purpose: The aim of this in vitro study was to investigate the effect of repeated firing on color stability and microstructure changes using X-ray diffraction, EDAX and SEM of two pressable ceramics.

Methods: A total number of forty eight freshly extracted maxillary central incisors were collected. The selected teeth were cleaned and disinfected in $0.5 \%$ sodium hypochlorite solution, then stored in distilled water for maximum two weeks until the testing began. The roots of the selected teeth were serrated with a disc for retention. The teeth were mounted vertically into autopolymerizing acrylic resin material. Full coverage all-ceramic preparation was performed for all teeth. The prepared teeth were randomly divided into two equal test groups $(n=24)$ according to the all-ceramic materials used for crown fabrication as follows: Group I: IPS e-max Press (LD): Twenty four prepared teeth were restored with pressable lithium di-silicate glass ceramics (IPS e.max press, Ivoclar, Vivadent AG, Schann, Lieshtenstein). Group II: Celtra Press (ZL): Twenty four prepared teeth were restored with pressable zirconia-reinforced lithium di-silicate glass ceramics (Celtra Press, Dentsply, Sirona.). Then samples were subjected to repeated firing cycles up to five firing cycles. Samples were divided into four equal subgroups $(n=6)$, according to the number of firing cycles performed for each sample. Subgroup (A) : Control samples, subgroup (B): $1^{\text {st }}$ firing cycle subgroup (C): $3^{\text {rd }}$ firing cycle, Subgroup (D): $5^{\text {th }}$ firing cycle. All ceramic crowns fabrication was done according to manufacturer instructions for each material. For each crown the $\mathrm{L}^{*}, \mathrm{a}^{*}$ and $\mathrm{b}^{*}$ was measured using spectrophotometer (Vita Easy shade) by placing the probe tip on the central part of the labial surface of the crown, the colorimetric values of $\Delta \mathrm{L}^{*}, \Delta \mathrm{a}^{*}$ and $\Delta \mathrm{b}^{*}$ were measured from differences in the respective $\mathrm{L}^{*}, \mathrm{a}^{*}$ and $\mathrm{b}^{*}$ values. The total color difference $\Delta \mathrm{E}^{*}$ were measured at each firing cycles subgroups for each group of ceramic materials. Data were collected, tabulated and statistically analyzed. Microstructural analysis for the two tested all ceramic materials was examined by X-ray diffractometer, scanning electron microscopy, the elemental chemical composition as well as quantitative analysis was measured by energy dispersive $\mathrm{X}$-ray spectroscopy (EDAX).This analysis was done after the control firing and the $5^{\text {th }}$ firing cycle.
\end{abstract}

* Associate Professor, Fixed Prosthodontics Department, Faculty of Dentistry, Cairo University, Egypt, Associate Professor, Fixed Prosthodontics Division, Oral and Maxillofacial Department, Faculty of Dentistry, Umm Al-Qura University. 
Results: Regardless of the ceramic material, statistically significant color differences were resulted by repeated firing as follows ; perceptible but yet clinically acceptable for lithium disilicate glass ceramics (LD), whereas, perceptible and clinically unacceptable for zirconia reinforced lithium di-silicate(ZL). The microstructure of the two pressable ceramic materials (LD, ZL) turned out to be unstable after repeated firing cycles for both ceramic materials.

Conclusions: Color stability is affected by repeated firing for both tested materials. Repeated firing is not recommended for ziconia reinforced lithium di-silicate because color changes $(\Delta \mathrm{E}$ $=4.18$ ) are exceeding the clinical acceptability.Repeated firings might result in microstructral changes within the ceramic materials.Microstructure analysis through SEM, EDAX and XRD is a reliable analytical approach.

KEY WORDS: Pressable ceramics, Microstructure, EDAX, Scanning electron microscope, XRD, Color stability, Repeated firing, Celtra Press, IPS e.max press.

\section{INTRODUCTION}

Dental ceramics have been used for long period in dentistry for producing more natural looking restorations due to their high esthetic and biomechanical properties ${ }^{(1)}$. For producing all ceramic restorations, lithium di-silicate, aluminum oxide, or zirconium oxide crystals were often used with variable processing techniques such as pressing, or $\mathrm{CAD} /$ CAM technique.

Lithium di-silicate glass ceramics gain admiration as metal free restorations. The material can be used for full contour restorations, inlays, onlays, and laminate veneer or can be used as core material with subsequent coating with veneering ceramics ${ }^{(2)}$.

Zirconia reinforced lithium di-silicate was developed in order to reinforce lithium di-silicate glass ceramics with nearly $20 \mathrm{wt} \%$ zirconia. This strengthening method may be attributed to precipitation of zirconia in glassy matrix leading to increased flexure strength to $405-553 \mathrm{Mpa}$ as compared to lithium di-silicate glass ceramics which is 300-441 Mpa and due to the positive esthetic features of glass ceramics with improved translucency, its use for fabrication of long span bridges, crowns, inlays, onlays, or veneers was granted ${ }^{(3)}$.

In routine aesthetic procedures, color match is achieved visually. Though environmental lighting conditions affect shade matching and selection.
Instrumental color measurements succeed over visual color assessment in terms of accuracy and efficiency because they afford objective, computable, reproducible, and more speedily attainable shade selections ${ }^{(4)}$.

Since one of the significant criteria for the clinical success of esthetic materials is color stability, therefore, evaluation of color changes using color measuring devices like colorimeters and spectrophotometers have become common. They offer accuracy, standardization and numerical expression of color. The data is reported in the CIE $L^{*} a^{*} b^{*}$ system which uses the three dimensional colorimetric measurements. $\mathrm{L}^{*}$ coordinate measure the lightness -darkness of the crown, the greater the $\mathrm{L}^{*}$, the lighter the crown. $\mathrm{a}^{*}$ measures the chroma along the red -green axis, a positive $\mathrm{a}^{*}$ indicates redness while a negative $a^{*}$ indicated greenness. $b^{*}$ measures the chroma along the yellow -blue axis positive $b^{*}$ indicates yellowness whereas negative $b^{*}$ indicates blueness .Then color changes $(\Delta \mathrm{E})$ are calculated using $\mathrm{L}^{*}, \mathrm{a}^{*}, \mathrm{~b}^{*(5)}$. The color changes $(\Delta E)$ reveals whether a change in the shade can be detected by a human observer ${ }^{(6)}$. Many studies ${ }^{(7,8)}$ considered color differences greater than 3.5 unit clinically unacceptable.

Mechanical properties interpose much to a long term clinical service of lithium disilicate glass ceramic restorations. Lithium di-silicate glass 
ceramics are constituted of an interlocking microstructure of a glass matrix and a crystalline phase $(9,10)$. This microstructure, which offers an effective strengthening and esthetic properties, is created by controlled crystallization of different components attained through controlling heat treatments ${ }^{(11,12)}$.

Firing cycles should encounter the requirements for a structural balance of the glassy and crystalline phases, as slight changes in the microstructure resulting from firing may harvest new chemical, physical and mechanical properties for a specific material ${ }^{(13)}$.

Some studies suggest that, ${ }^{(14,15)}$ depending on the firing protocol implemented, metal oxides responsible for the color of the material may become unstable and that heat treatment may lead to modification in the material constituents phases $^{(16-18)}$. Claus stated that the firing cycle temperature, temperature rate of increase ,holding time, and cooling time all affect the distribution of the sintering, glass, and crystal phase in the microstructure of porcelain ${ }^{(19)}$. Therefore, it is important that researchers gather more information regarding the effect of repeated firing on optical properties and microstructure of all ceramic restoration. The aim of this in vitro study was to investigate the effect of repeated firing on color and microstructure changes of two pressable ceramics. The null hypotheses were that (1) the color stability of two pressable ceramics would not be affected by repeated firing cycles and (2) microstructure of the two materials might not be affected by repeated firing cycles.

\section{MATERIAL AND METHODS}

\section{Teeth selection and preparation:}

A total number of forty eight freshly extracted maxillary central incisors were collected. The selected teeth were inspected for absence of caries, or cracks. A comparable bucco-lingual, mesio-distal and ocluso-gingival dimensions of the selected teeth was checked ; these dimensions were measured at the cemento-enamel junction, height of contour and the occluso-axial line angles in millimeters using digital caliper $(0-50 \mathrm{~mm}, 0.01 \mathrm{~mm}$, Germany). The selected teeth were cleaned and disinfected in $0.5 \%$ sodium hypochlorite solution, then stored in distilled water for maximum two weeks until the testing began.

The roots of the selected teeth were serrated with a disc for retention. The teeth were mounted vertically into auto-polymerizing acrylic resin material (Technovit 4000, Heraeus Kulzer, Wehrheim, Germany) using Teflon mold. The cemento-enamel junction of each tooth is adjusted to be higher than the top of the template by $2 \mathrm{~mm}$. Full coverage allceramic preparation was performed for all teeth using high-speed handpiece (Midwest Dentsply, Desplaines, IL) connected to dental surveyor (Degussa F1; Degudent, Hanau, Germany) to obtain a standardized preparation. The preparation was standardized to be: $2 \mathrm{~mm}$ incisal reduction, uniform two planes facial reduction of $1.2 \mathrm{~mm}, 1.5 \mathrm{~mm}$ at the palatal fossa. The axial surfaces were prepared with a total 6 degrees convergence angle from the vertical axis of the tooth with $1.5 \mathrm{~mm}$ shoulder finish line with rounded internal line angle placed $1 \mathrm{~mm}$ above the cemento-enamel junction ${ }^{(20)}$.All prepared teeth used in this study were prepared by the same operator.

\section{Sample grouping:}

The prepared teeth were randomly divided into two equal test groups $(n=24)$ according to the allceramic materials used for crown fabrication as follows:

Group I: IPS e-max Press (LD): Twenty four prepared teeth were restored with IPS e.max press lithium disilicate glass ceramics (IPS e.max press, Ivoclar, Vivadent AG, Schann, Lieshtenstein). Group II: Celtra Press (ZL): Twenty four prepared teeth were restored with Celtra press zirconia-reinforced lithium disilicate glass ceramics (Celtra Press, 
Dentsply, Sirona). The selected shade for both materials was $\mathrm{A}_{2}$. Then the samples were subjected to repeated firing cycles up to five firing cycles. Samples were divided into four equal subgroups $(n=6)$, according to the number of firing cycles performed for each sample. Subgroup (A) : Control samples ,subgroup (B): $1^{\text {st }}$ firing cycle ,subgroup (C): $3^{\text {rd }}$ firing cycle, Subgroup (D): $5^{\text {th }}$ firing cycle, (Table 1). The chemical composition and manufacturers of the materials used in this study are presented in (Table 2).

\section{All-Ceramic crowns fabrication}

All the prepared teeth were assigned equally for group I (LD): IPS e-max press all-ceramic crowns $(n=24)$ and group II (ZL): Celtra press all-ceramic crowns $(n=24)$. Both were constructed using heat pressing technique using $A_{2}$ ceramic ingots, all prepared teeth were scanned using inLab scanner (InEos, Sirona, Germany), designed using software (InLab SW4.0, Sirona)and milled using CAD/CAM milling machine (Cerec-inLab MC XL, Sirona, Germany). Virtual non-anatomic wax pattern which had an incisal cut-back shape for porcelain layering technique was digitally designed; the designed parameters were set as follows: $0.8 \mathrm{~mm}$ incisally, 1.2 $\mathrm{mm}$ for axial surfaces and $50 \mu \mathrm{m}$ cement thickness. The CAD/CAM milled wax patterns were sprued and invested in IPS Press Vest investment material (Ivoclar, Vivadent) for group I or Celtra press investment material (Dentsply, Sirona) for group II and the crowns were pressed in IPS e-max pressable ceramic or Celtra press ceramic according to manufacturer's instructions. Following pressing, divesting was done using airborne particle abrasion (50 $\mu \mathrm{m}$ $\mathrm{Al}_{2} \mathrm{O}_{3}$ at 1 bar, $\left.30 \mathrm{PSI}\right)$. Removal of the sprues and finishing were done using fine diamond disc (\#940; Brasseler, Savannah,Ga) and grinding instruments according to manufacturer's instructions. Restorations were examined for any deformity or defects, and then placed in ultrasonic bath and steam for debris removal. Feldspathic porcelain matched with each system (IPs e.max ceram, Ivoclar, Vivadent and Celtra press ceram, Dentsply, Sirona) was used to complete the incisal morphology by using a silicon putty cut-back matrix which was taken for all teeth before preparation. All crowns were done by the same experienced dental technician.

TABLE (1) Samples grouping.

\begin{tabular}{|c|c|c|c|c|c|c|c|c|}
\hline Group & \multicolumn{4}{|c|}{$\begin{array}{l}\text { IPS e.max press } \\
\qquad(\mathrm{n}=\mathbf{2 4})\end{array}$} & \multicolumn{4}{|c|}{$\begin{array}{l}\text { Celtra Press } \\
\qquad(n=24)\end{array}$} \\
\hline Firing cycles & $\begin{array}{c}\text { Control } \\
\text { firing } \\
(n=6)\end{array}$ & $\begin{array}{c}1^{\text {st }} \\
\text { Firing } \\
(\mathrm{n}=6)\end{array}$ & $\begin{array}{c}3^{\text {rd }} \\
\text { Firing } \\
(n=6)\end{array}$ & $\begin{array}{c}5^{\text {th }} \\
\text { Firing } \\
(n=6)\end{array}$ & $\begin{array}{c}\text { Control } \\
\text { firing } \\
(\mathrm{n}=6)\end{array}$ & $\begin{array}{c}1^{\text {st }} \\
\text { Firing } \\
(n=6)\end{array}$ & $\begin{array}{c}3^{\text {rd }} \\
\text { Firing } \\
(n=6)\end{array}$ & $\begin{array}{c}5^{\text {th }} \\
\text { Firing } \\
(n=6)\end{array}$ \\
\hline
\end{tabular}

TABLE (2) The chemical composition and manufacturers of the materials used in this study.

\begin{tabular}{|l|l|l|}
\hline Material & Composition & Manufacturer \\
\hline IPS e-max Press & $\mathrm{SiO}_{2}, \mathrm{Li}_{2} \mathrm{O}, \mathrm{K}_{2} \mathrm{O}, \mathrm{P}_{2} \mathrm{O}_{5}, \mathrm{ZrO}_{2}, \mathrm{ZnO}$, other oxides and ceramic pigments & Ivoclar Vivadent \\
\hline Celtra Press & $\mathrm{SiO}_{2}, \mathrm{Li}_{2} \mathrm{O}, \mathrm{ZrO}_{2}, \mathrm{P}_{2} \mathrm{O}_{5}, \mathrm{Al}_{2} \mathrm{O}_{3}, \mathrm{~K}_{2} \mathrm{O}, \mathrm{CeO}_{2}$, other oxides and pigments & Dentsply; Konstanz, Germany \\
\hline
\end{tabular}




\section{Repeated firing:}

After surface finishing and polishing, each sample was placed in its own furnace for the wash firing program, this firing cycle served to release stresses associated with the grinding and polishing procedures as recommended by the manufacturers named subgroup A: control firing cycle $(n=6)$ for each group. Six crowns from each material group were taken and designated for first firing cycle, subgroup B: $1^{\text {st }}$ time firing cycle $(n=6)$, subgroup C: $3^{\text {rd }}$ time firing cycle $(n=6)$, subgroup D: $5^{\text {th }}$ time firing cycle $(n=6)$. The firing cycles were done according to the manufacturer's instructions as illustrated in (Table 3,4).

\section{Color measurement}

Each crown was seated on its corresponding prepared tooth, tightly secured in its place using a specially designed holding device. For each crown the $\mathrm{L}^{*}, \mathrm{a}^{*}$ and $\mathrm{b}^{*}$ was measured by placing the probe tip for Vita Easy shade system (Vita Easy shade, Ivoclar, Vivadent AG, Schann, Liechtenstein) on the central part of the labial surface of the crown, ${ }^{(4)}$. To ensure consistency of consecutively repeated color measurements, probe tip was positioned at the same place on each specimen for different color measurements.

TABLE (3) Firing program for IPS e.max Ceram.

\begin{tabular}{|c|c|c|c|c|c|c|c|}
\hline Firing & Low Temp & $\begin{array}{l}\text { Dry Time } \\
\text { (min) }\end{array}$ & $\begin{array}{c}\text { Temp } \\
\text { Increase }\end{array}$ & $\begin{array}{l}\text { High } \\
\text { Temp }\end{array}$ & $\begin{array}{l}\text { Hold } \\
(\min )\end{array}$ & $\begin{array}{l}\text { Vacuum start } \\
\text { Temp }\end{array}$ & $\begin{array}{c}\text { Vacuum End } \\
\text { Temp }\end{array}$ \\
\hline $\begin{array}{c}\text { Wash Firing (Control } \\
\text { Firing cycle) }\end{array}$ & $403^{\circ} \mathrm{c}$ & 4 & $50^{\circ} \mathrm{c} / \mathrm{min}$ & $750^{\circ} \mathrm{c}$ & 1 & $450^{\circ} \mathrm{c}$ & $749^{\circ} \mathrm{c}$ \\
\hline $\begin{array}{l}\text { First incisal firing } \\
\left(1^{\text {st }} \text { Firing cycle }\right)\end{array}$ & $403^{\circ} \mathrm{c}$ & 4 & $50^{\circ} \mathrm{c} / \mathrm{min}$ & $750^{\circ} \mathrm{c}$ & 1 & $450^{\circ} \mathrm{c}$ & $749^{\circ} \mathrm{c}$ \\
\hline $\begin{array}{c}\text { Second incisal Firing } \\
\left(3^{\text {rd }} \text { Firing cycle }\right)\end{array}$ & $403^{\circ} \mathrm{c}$ & 4 & $50^{\circ} \mathrm{c} / \mathrm{min}$ & $750^{\circ} \mathrm{c}$ & 1 & $450^{\circ} \mathrm{c}$ & $749^{\circ} \mathrm{c}$ \\
\hline $\begin{array}{c}\text { Glaze Firing } \\
\left(5^{\text {th }} \text { Firing cycle }\right)\end{array}$ & $403^{\circ} \mathrm{c}$ & 6 & $50^{\circ} \mathrm{c} / \mathrm{min}$ & $725^{\circ} \mathrm{c}$ & 1 & $450^{\circ} \mathrm{c}$ & $749^{\circ} \mathrm{c}$ \\
\hline
\end{tabular}

TABLE (4) Firing program for Celtra Ceram.

\begin{tabular}{|c|c|c|c|c|c|c|c|c|c|c|c|c|c|c|c|}
\hline \multirow{2}{*}{ Firing } & \multicolumn{2}{|c|}{ Drying } & \multirow{2}{*}{$\begin{array}{c}\text { Closing } \\
\text { Min }\end{array}$} & \multicolumn{2}{|c|}{ Preheating } & \multicolumn{3}{|c|}{ Vaccum } & \multirow{2}{*}{$\begin{array}{c}\begin{array}{c}\text { Heating } \\
\text { rate }\end{array} \\
\mathrm{C}^{0} / \mathrm{min}\end{array}$} & \multirow{2}{*}{$\begin{array}{c}\text { Final } \\
\text { Temp } \\
\mathrm{C}^{0}\end{array}$} & \multirow{2}{*}{$\begin{array}{c}\text { Vacuum } \\
\text { time } \\
\mathrm{V} \\
\mathrm{min}\end{array}$} & \multirow{2}{*}{$\begin{array}{c}\text { Holding } \\
\text { time } \\
\text { min }\end{array}$} & \multicolumn{2}{|c|}{ Temperate } & \multirow{2}{*}{$\begin{array}{c}\text { Cooling } \\
\text { min }\end{array}$} \\
\hline & $\mathrm{C}^{0}$ & Min & & $\mathrm{C}^{0}$ & $\min$ & $\begin{array}{l}\text { On/off/ } \\
\text { Cont. }\end{array}$ & $\begin{array}{l}\mathrm{On} / \\
\mathrm{C}^{0}\end{array}$ & $\begin{array}{l}\mathrm{On} / \\
\mathrm{C}^{0}\end{array}$ & & & & & Min & $\mathrm{C}^{0}$ & \\
\hline $\begin{array}{c}\text { Wash Firing (Control } \\
\text { Firing cycle) }\end{array}$ & 135 & 0 & 1 & 400 & 1 & Off & - & - & 55 & 760 & 0 & 2 & - & - & 0 \\
\hline $\begin{array}{l}\text { First incisal firing } \\
\left(1^{\text {st }} \text { Firing cycle }\right)\end{array}$ & 135 & 2 & 2 & 400 & 2 & Off & - & - & 55 & 760 & 0 & 2 & - & - & 5 \\
\hline $\begin{array}{c}\text { Second incisal Firing } \\
\left(3^{\text {rd }} \text { Firing cycle }\right)\end{array}$ & 135 & 2 & 2 & 400 & 2 & Off & - & - & 55 & 760 & 0 & 2 & - & - & 5 \\
\hline $\begin{array}{c}\text { Glaze Firing } \\
\left(5^{\text {th }} \text { Firing cycle }\right)\end{array}$ & 135 & 2 & 2 & 400 & 2 & Cont. & 400 & 760 & 55 & 760 & 1 & 1 & - & - & 5 \\
\hline
\end{tabular}


All color measurements were done three times for each sample. Tip of the Vita easy shade hand piece was firmly held in the calibration port and constantly held until the instrument sounded a beep to indicate that calibration was finished, The samples were positioned over a gray background and the spectrophotometer (Vita Easy shade) was used to determine the shade of the tooth according to the Vitapan classical shade guides. This was done while the device was adjusted at "tooth single" mode. Then the shade and the CIELAB coordinates were measured on the crown samples by selecting the "restoration mode" and preselecting shade A2 on the device menu, the screen then revealed the difference between the default pre-entered shade and the measured shade of the crown samples. The $\mathrm{L}^{*}, \mathrm{a}^{*}, \mathrm{~b}^{*}$ values for the selected shade was shown on the screen as well.

The commission International de l'Eclairage (CIE L* $\mathrm{a}^{*}, \mathrm{~b}^{*}$ ) color space was used to determine color differences ${ }^{(4)} . \Delta \mathrm{L}^{*}, \Delta \mathrm{a}^{*}$ and $\Delta \mathrm{b}^{*}$ are the differences between two colors in the CIE based color space ${ }^{(4)}$. In this study, the colorimetric values of $\Delta \mathrm{L}^{*}, \Delta \mathrm{a}^{*}$ and $\Delta \mathrm{b}^{*}$ were measured from differences in the respective $\mathrm{L}^{*}, \mathrm{a}^{*}$ and $\mathrm{b}^{*}$ values. The total color difference $\Delta \mathrm{E}^{*}$ between two colors was measured. Each given in terms of $\mathrm{L}^{*}, \mathrm{a}^{*}$ and $\mathrm{b}^{*}$ was calculated from the following formula:

$\Delta \mathrm{E}^{*}=\left[\left(\Delta \mathrm{L}^{*}\right)^{2}+\left(\Delta \mathrm{a}^{*}\right)^{2}+\left(\Delta \mathrm{b}^{*}\right)^{2}\right]^{1 / 2}$. Data were collected, tabulated and statistically analyzed. Mean $\Delta \mathrm{E}$ values below 3.0 were considered clinically imperceptible, $\Delta \mathrm{E}$ values between 3.0 and 5.0 were considered clinically acceptable and $\Delta \mathrm{E}$ values above 5.0 were considered clinically unacceptable. These $\Delta \mathrm{E}$ values were based on average acceptability and perceptibility thresholds from previous studies ${ }^{(21-26)}$.

\section{Microstructural Analysis:}

For each material group, the control firing samples, subgroup (A) $(n=6)$ for each material group were divided equally. Three samples were submitted to XRD to determine its crystallization phase. Control firing samples were placed on the holder of X-ray diffractometer (XRD, D8 advance, Bruker AXS, Germany) and scanned using $\mathrm{Cuk}_{\alpha 1}$ $\mathrm{X}$-ray angle. The XRD pattern was gathered over the angular range 10-20 degrees, $2 \Theta$ with step size and counting time of 0.009 degrees $2 \Theta$ degrees and $3 \mathrm{~s}$ - step interval respectively, incident radiation $(\lambda=1.5406 \breve{A})$ and, The crystalline phases for the two materials were recognized using the PDf 2 database integrated in the evaluation package Diffract plus (Diffract plus Basic, EVA, Bruker AXS, Germany).

The other three samples from the control firing sub group (A) were investigated by scanning electron microscopy (SEM; Quanta 250, FEG). Samples were cleaned, dried and sputter coated with gold to examine the microstructure of the materials at magnifications of (X5000, and $\mathrm{X} 10000$ ). EDAX energy dispersive $\mathrm{X}$-ray analysis was used to quantify elements and to assess the chemical composition by x-ray microanalysis (FEI Czech SEM-USA). The EDAX spectra were taken in the energy range $0.1-10 \mathrm{keV}$ at random locations. Microstructural analysis (XRD, SEM and EDAX) was repeated after the $5^{\text {th }}$ firing cycle subgroup (D).

\section{Statistical Analysis}

Numerical data were explored for normality by checking the distribution of data and using tests of normality (Kolmogorov-Smirnov and ShapiroWilk tests). Color change $(\Delta \mathrm{E})$ data showed normal (parametric) distribution. Data were presented as mean and standard deviation (SD) values. Repeated measures Analysis of Variance (ANOVA) was used to study the effect of material, firing cycles and their interaction on mean $\Delta \mathrm{E}$. Bonferroni's post-hoc test was used for pair-wise comparisons when ANOVA test is significant. The significance level was set at $\mathrm{P} \leq 0.05$. Statistical analysis was performed with IBM SPSS Statistics for Windows, Version 23.0. Armonk, NY: IBM Corp. 


\section{RESULTS}

Repeated measures ANOVA test results showed that ceramic material regardless of firing cycles had a statistically significant effect on mean $\Delta \mathrm{E}$. Firing cycles regardless of ceramic material used had a statistically significant effect on mean $\Delta \mathrm{E}$. The interaction between the two variables had no statistically significant effect on mean $\Delta \mathrm{E}$ indicating that the variables are independent from each other (Table 5).

Regardless the firing cycles; IPS e.max press (LD) showed statistically significant lower mean
$\Delta \mathrm{E}$ than Celtra press (ZL) $(P$-value $=0.020$, Effect size $=0.512$ ) while there was a statistically significant difference between mean $\Delta \mathrm{E}$ at different firing cycles regardless of the ceramic material used in this study; $(P$-value $<0.001$, Effect size $=0.749)$. Pair-wise comparisons between firing cycles revealed that there was a statistically significant increase in mean $\Delta \mathrm{E}$ after $1^{\text {st }}$ cycle followed by a statistically significant decrease in mean $\Delta \mathrm{E}$ from $1^{\text {st }}$ to $3^{\text {rd }}$ cycle. There was a statistically significant increase in mean $\Delta \mathrm{E}$ from $3^{\text {rd }}$ to $5^{\text {th }}$ cycle (Fig. 1,2 $\&$ Table 6,7).

TABLE (5) Repeated measures ANOVA results for the effect of different variables on mean $\Delta \mathrm{E}$.

\begin{tabular}{|l|c|c|c|c|c|c|}
\hline \multicolumn{1}{|c|}{ Source of variation } & $\begin{array}{c}\text { Type III Sum } \\
\text { of Squares }\end{array}$ & Df & $\begin{array}{c}\text { Mean } \\
\text { Square }\end{array}$ & F-value & P-value & $\begin{array}{c}\text { Effect size } \\
\text { (Partial eta squared) }\end{array}$ \\
\hline Material & 7.140 & 1 & 7.140 & 8.392 & $0.020 *$ & 0.512 \\
\hline Firing cycles & 7.075 & 3 & 2.358 & 23.891 & $<0.001 *$ & 0.749 \\
\hline Material x Firing cycles interaction & 0.289 & 3 & 0.096 & 0.975 & 0.421 & 0.109 \\
\hline
\end{tabular}

df: degrees of freedom $=(n-1), *$ : Significant at $P \leq 0.05$

TABLE (6) The mean, standard deviation (SD) values and results of repeated measures ANOVA test for comparison between $\Delta \mathrm{E}$ of the two materials regardless of firing cycles.

\begin{tabular}{|c|c|c|c|c|c|}
\hline \multicolumn{2}{|c|}{ IPS e.max press } & \multicolumn{2}{c|}{ Celtra press } & \multirow{2}{*}{ P-value } & $\begin{array}{c}\text { Effect size } \\
\text { (Partial eta squared) }\end{array}$ \\
\hline Mean & SD & Mean & SD & $0.020^{*}$ & 0.512 \\
\hline
\end{tabular}

*: Significant at $P \leq 0.05$

TABLE (7) The mean, standard deviation (SD) values and results of repeated measures ANOVA test for comparison between $\Delta \mathrm{E}$ of different Firing cycles regardless of material.

\begin{tabular}{|c|c|c|c|c|c|c|c|c|c|}
\hline \multicolumn{2}{|c|}{ Control Firing cycle } & \multicolumn{2}{|c|}{$1^{\text {st }}$ Firing cycle } & \multicolumn{2}{|c|}{$3^{\text {rd }}$ Firing cycle } & $5^{\text {th }}$ Firing cycle & \multirow{2}{*}{ P-value } & $\begin{array}{c}\text { Effect size } \\
\text { (Partial eta squared) }\end{array}$ \\
\cline { 1 - 6 } Mean & SD & Mean & SD & Mean & SD & Mean & SD & & 0.749 \\
\hline
\end{tabular}

*: Significant at $P \leq 0.05$, Different superscripts are statistically significantly different 


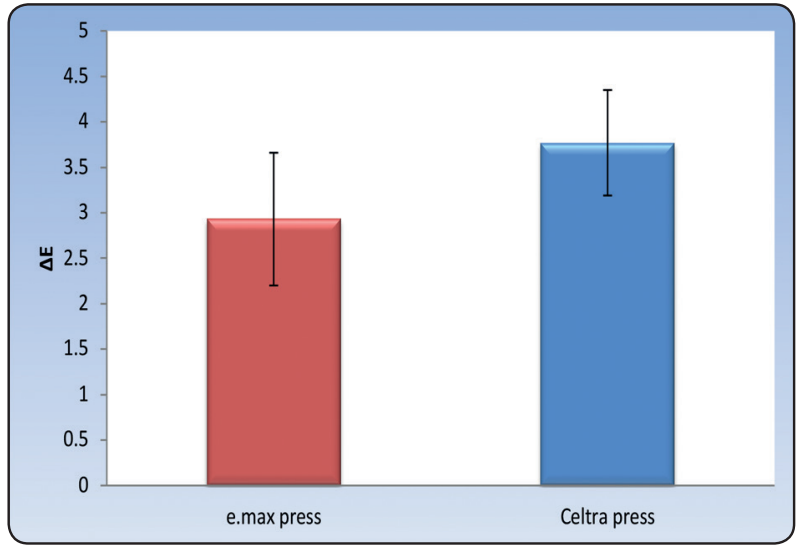

Fig. (1) Bar chart represents mean and standard deviation values for $\Delta \mathrm{E}$ of the two materials regardless of firing cycles.

Effect of different interactions on $\Delta \mathrm{E}$, showed that there was no statistically significant difference between mean $\Delta \mathrm{E}$ of the two materials for the control samples $(P$-value $=0.165$, Effect size $=0.226)$. While for $1^{\text {st }}, 3^{\text {rd }}$ as well as $5^{\text {th }}$ firing cycles; IPS e.max press glass ceramics showed a statistically significantly lower mean $\Delta \mathrm{E}$ than Celtra press glass ceramics $(P$-value $=0.020$, Effect size $=$ $0.509),(P$-value $=0.026$, Effect size $=0.481)$ and $(P$-value $=0.016$, Effect size $=0.535)$, respectively. Whether with IPS e.max press or Celtra press; there

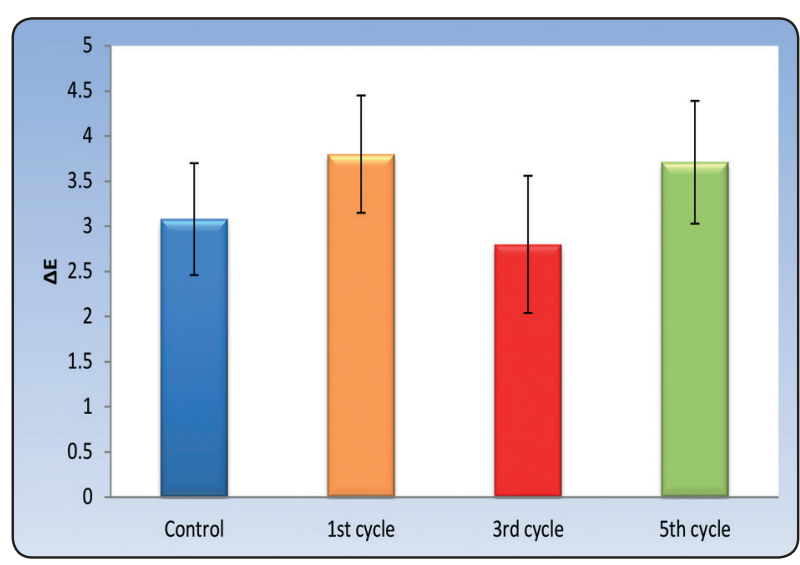

Fig. (2) Bar chart represents mean and standard deviation values for $\Delta \mathrm{E}$ of different firing cycles regardless of material.

was a statistically significant difference between mean $\Delta \mathrm{E}$ at different firing cycles $(P$-value $=0.003$, Effect size $=0.893)$ and $(P$-value $=0.002$, Effect size $=0.900)$, respectively. Pair-wise comparisons between the firing cycles revealed that there was a statistically significant increase in mean $\Delta \mathrm{E}$ at $1^{\text {st }}$ firing cycle. From $1^{\text {st }}$ to $3^{\text {rd }}$ firing cycles, there was a statistically significant decrease in mean $\Delta \mathrm{E}$. From $3^{\text {rd }}$ to $5^{\text {th }}$ firing cycles, there was a statistically significant increase in mean $\Delta \mathrm{E}$ (Fig.3, Table 8).

TABLE (8) The mean, standard deviation (SD) values and results of repeated measures ANOVA test for comparison between $\Delta \mathrm{E}$ values with different interactions of variables

\begin{tabular}{|c|c|c|c|c|c|c|}
\hline \multirow{2}{*}{ Firing cycles } & \multicolumn{2}{|c|}{ IPS e.max press } & \multicolumn{2}{|c|}{ Celtra press } & \multirow{2}{*}{$P$-value } & \multirow{2}{*}{$\begin{array}{c}\text { Effect size } \\
(\text { Partial eta squared })\end{array}$} \\
\hline & Mean & $\mathrm{SD}$ & Mean & $\mathrm{SD}$ & & \\
\hline Control & $2.8^{\text {в }}$ & 0.7 & $3.36^{\mathrm{B}}$ & 0.43 & 0.165 & 0.226 \\
\hline $1^{\mathrm{st}}$ & $3.36^{\mathrm{A}}$ & 0.57 & $4.24^{\mathrm{A}}$ & 0.38 & $0.020 *$ & 0.509 \\
\hline $3^{\text {rd }}$ & $2.3^{\text {в }}$ & 0.77 & $3.3^{\text {в }}$ & 0.29 & $0.026^{*}$ & 0.481 \\
\hline $5^{\text {th }}$ & $3.24^{\mathrm{A}}$ & 0.54 & $4.18^{\mathrm{A}}$ & 0.43 & $0.016^{*}$ & 0.535 \\
\hline$P$-value & \multicolumn{2}{|c|}{$0.003 *$} & \multicolumn{2}{|c|}{$0.002 *$} & & \\
\hline $\begin{array}{l}\text { Effect size } \\
\text { (Partial eta squared) }\end{array}$ & \multicolumn{2}{|c|}{0.893} & \multicolumn{2}{|c|}{0.900} & & \\
\hline
\end{tabular}

*: Significant at $P \leq 0.05$, Different superscripts in the same column are statistically significantly different 


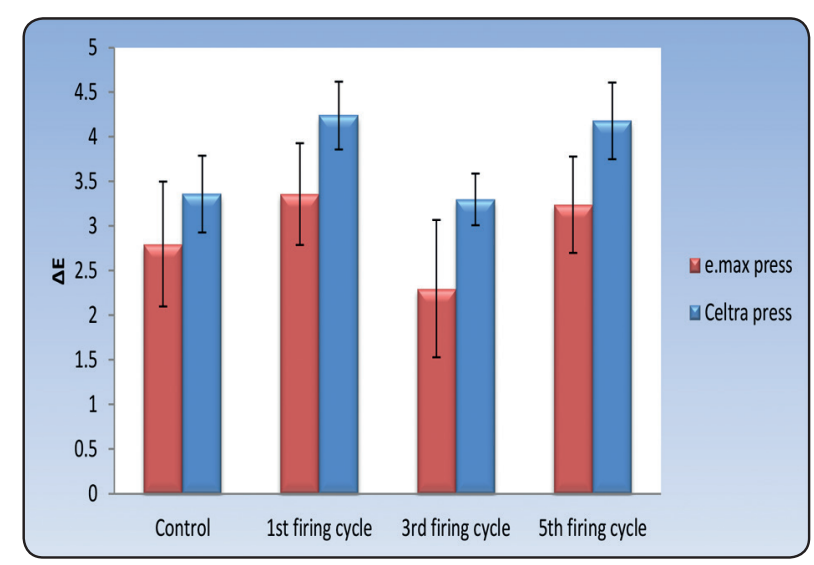

Fig. (3) Bar chart represents mean and standard deviation values for $\Delta \mathrm{E}$ of different variables.

\section{X-ray Diffraction Analysis (XRD)}

X-ray diffraction analysis inspects the crystalline material structure, including atomic arrangement, crystal size and imperfections .For lithium disilicate (LD) and zirconia reinforced lithium disilicate (ZL)the measurement parameters were: angular scan range $10-45^{\circ} 2 \Theta$, incident radiation

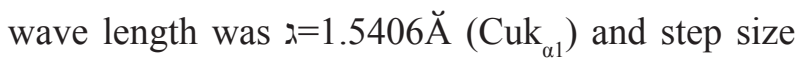
and counting time of $0.009^{\circ} 2 \Theta$ and $3 \mathrm{~s}$, respectively. Regarding Lithium di-silicate Ceramic material, the X-ray analysis (XRD) of the control samples revealed that the microstructure is a finger print amorphous phase with no crystalline structure, so no dominant peaks were detected (Fig. 4A) whereas the $5^{\text {th }}$ firing samples for the same material, zirconia reinforced lithium di-silicate for the control samples and the $5^{\text {th }}$ firing samples revealed that a crystalline structure was noticed with highest peaks of lithium di-silicate which was recognized to be the main crystalline phase(Fig. 4B,5 A,5B). Dominant peaks for lithium di-silicate $\left(\mathrm{Li}_{2} \mathrm{Si}_{2} \mathrm{O}_{5}\right)$ were detected at $2 \mathrm{O}$ values of $23.75,24.26,24.8$ and 37.5 degrees. The highest peak was at 23.75 degrees corresponding to the standard peaks for lithium di-silicate, while Dominant peaks for lithium phosphate $\left(\mathrm{Li}_{3} \mathrm{PO}_{4}\right)$ were detected at $2 \Theta$ values of $22.25,24.26,24.66$ and 24.72 degrees. The highest peak was at 22.25 degrees corresponding to the standard peaks for lithium phosphate (Fig. 4B,5 A,5B).The XRD data showed that peaks for control firing and $5^{\text {th }}$ repeated firing for celtra press are similar, the crystalline phase did not change while for IPS e.max press the microstructure changed from amorphous to crystalline phase.

\section{Scanning electron microscope}

Representative SEM images of both materials namely; IPS e.max press and Celtra press showed a typical microstructure of glass ceramics with ceramic crystals embedded and dissolved in glassy matrix. The SEM image analysis at (X5000, X10000) revealed that; for IPS e.max Press group, the length of the crystals averaged $3.06 \mu \mathrm{m}$ in length while averaged $463 \mathrm{~nm}$ in width compared to the $5^{\text {th }}$ firing samples in the same group where the crystals measured $4.03 \mu \mathrm{m}$ in length and $500 \mathrm{~nm}$ in width (Fig.6A,6B,8A,8B), while for Celtra Press group the length of the crystals averaged $3.86 \mu \mathrm{m}$ in length, $456 \mathrm{~nm}$ in width for the control firing cycle while for the $5^{\text {th }}$ firing cycle, crystals measured $4.34 \mu \mathrm{m}$ in length and 4.87nm in width (Fig.7A,7B,9A,9B). So, there was a noticeable increase in crystal averaged dimensions after repeated firing for both materials.

\section{Energy Dispersive X-Ray Analysis (EDAX)}

Energy Dispersive X-Ray Analysis (EDAX), is a non-destructive technique which depends upon $\mathrm{x}$-ray to recognize the elemental composition of materials with little or no sample preparation, it is attached to Scanning Electron Microscopy where the imaging capabilities of the microscope detects the specimen of interest. The produced data from the EDAX shows peaks corresponding to the dominant element formulating the actual composition of the material being analyzed. It can be Qualitative, Semiquantitative and quantitative; moreover it produces element distribution through element mapping. EDAX results showed no change in composition between the two tested groups in both control firing and $5^{\text {th }}$ firing cycles. (Fig.10A, 10B, 11A, 11B) 


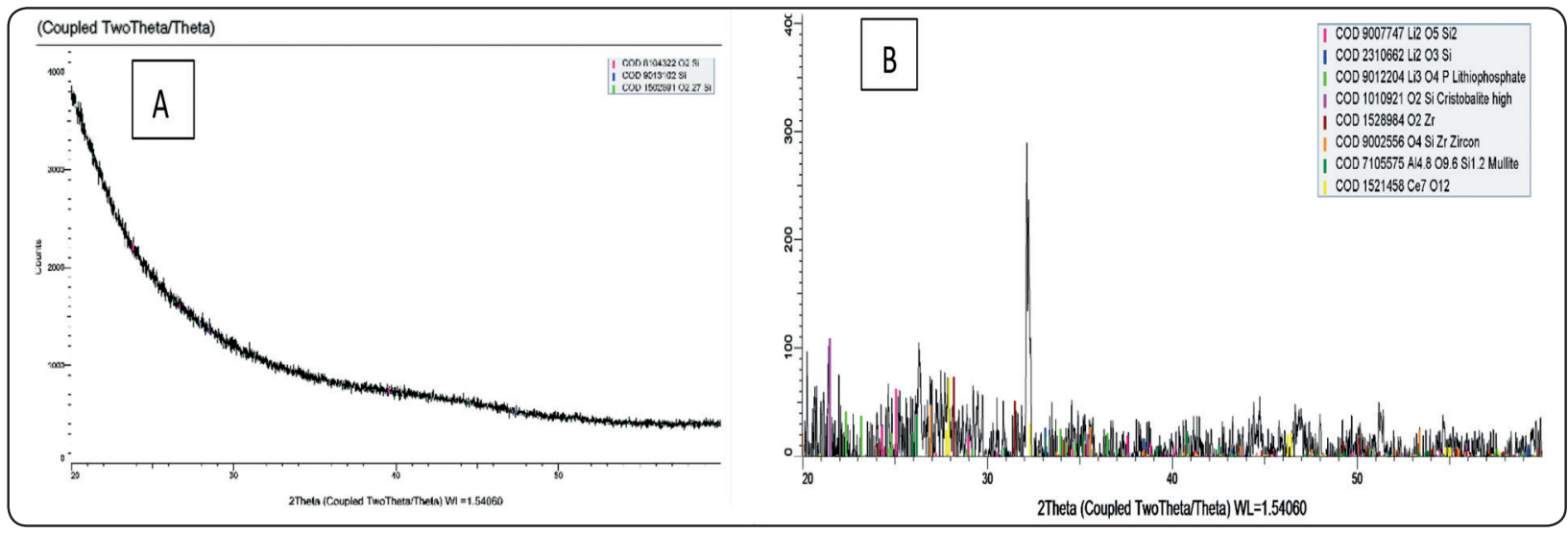

Fig. (4) XRD pattern for Lithium di-silicate glass ceramics (A) and Zirconia reinforced lithium disilicate glass ceramics(B) at control firing cycle.

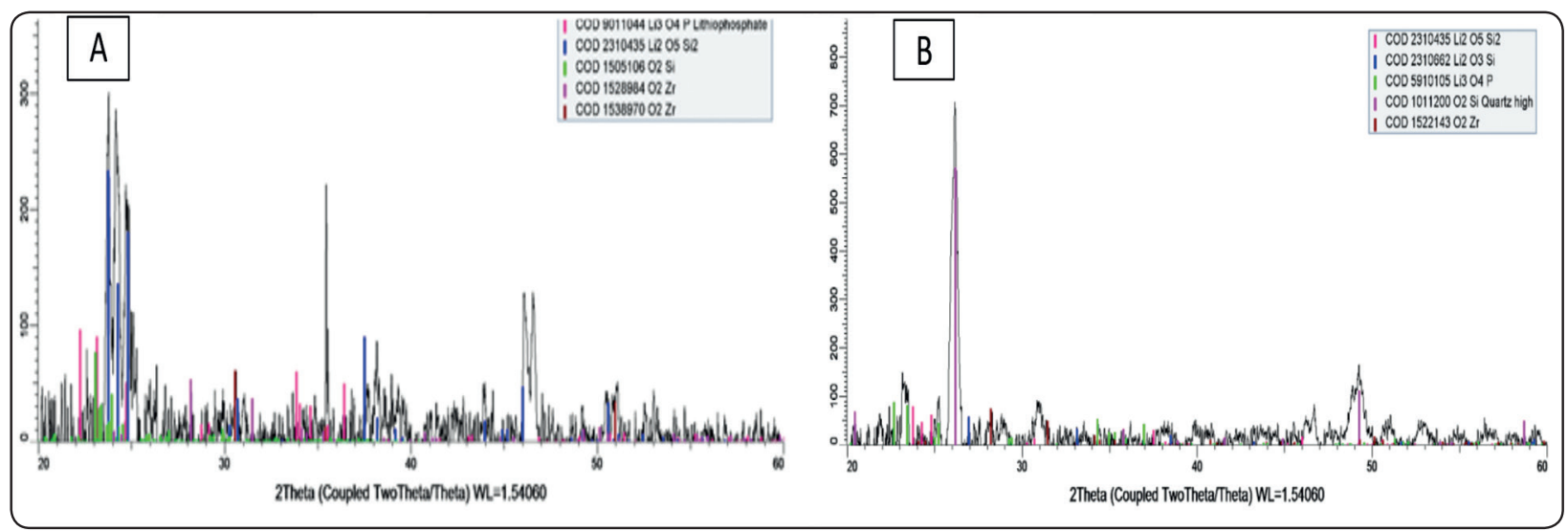

Fig. (5) XRD pattern for Lithium di-silicate glass ceramics (A) and Zirconia reinforced lithium disilicate glass ceramics (B) at $5^{\text {th }}$ firing cycle.

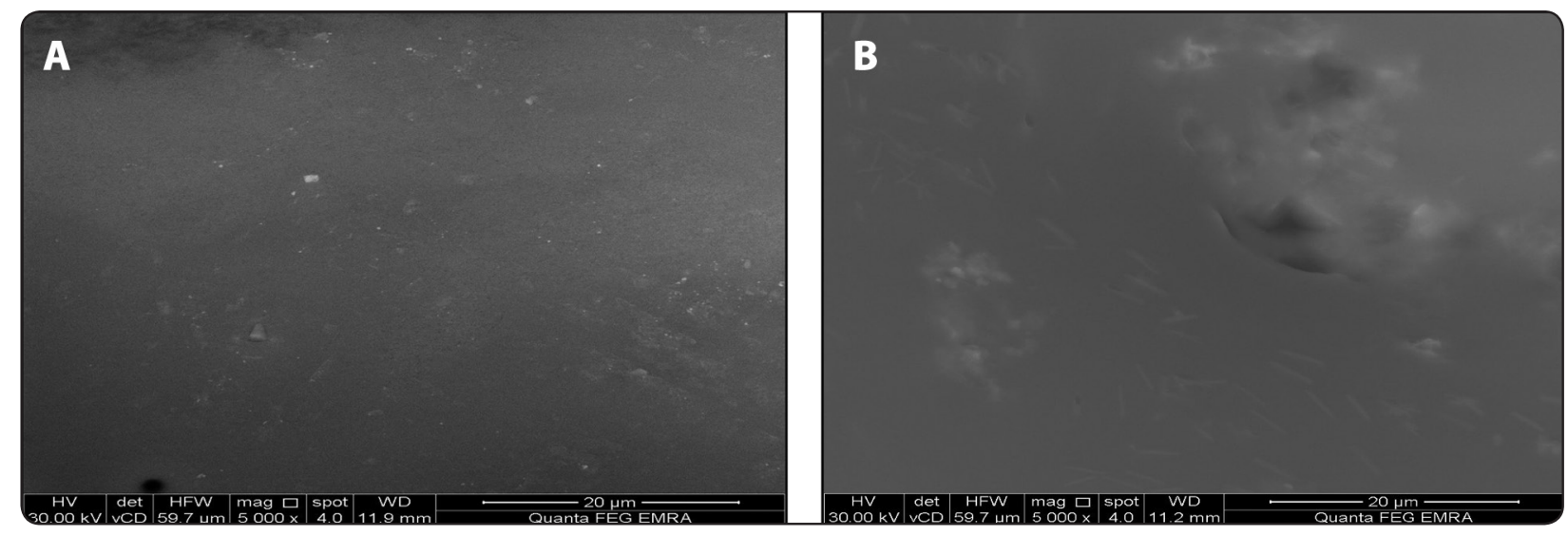

Fig. (6) Representative scanning electron microscope images (X5000) for IPS e.max press Where (A) represents control firing and (B) the $5^{\text {th }}$ firing cycle . 


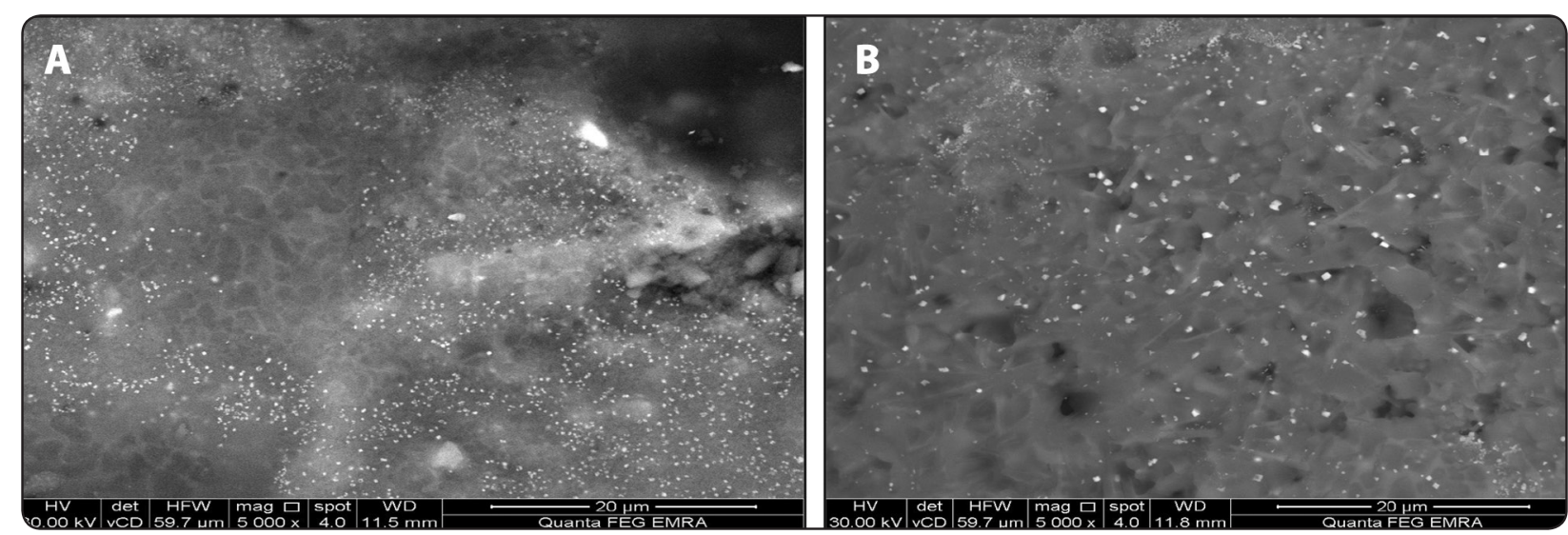

Fig. (7) Representative scanning electron microscope images (X5000) for Celtra press Where (A) represents control firing and (B) the $5^{\text {th }}$ firing cycle.

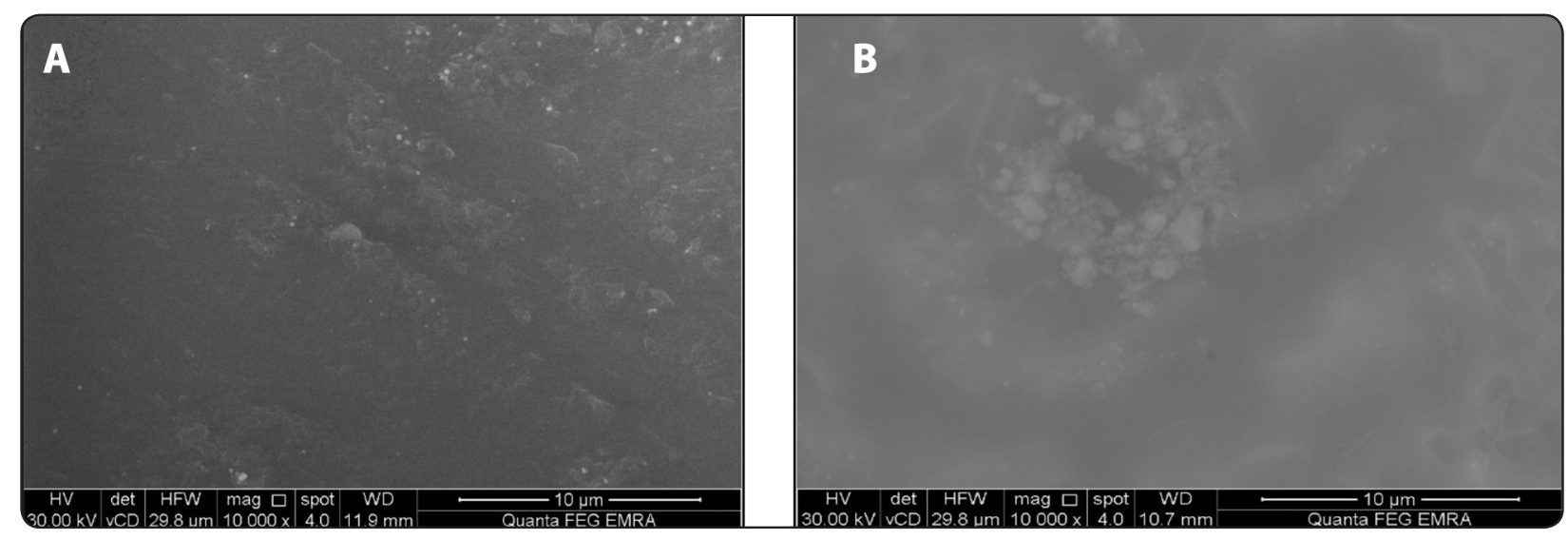

Fig. (8) Representative scanning electron microscope images (X10000) for IPS e.max press Where (A) represents control firing and (B) the $5^{\text {th }}$ firing cycle.

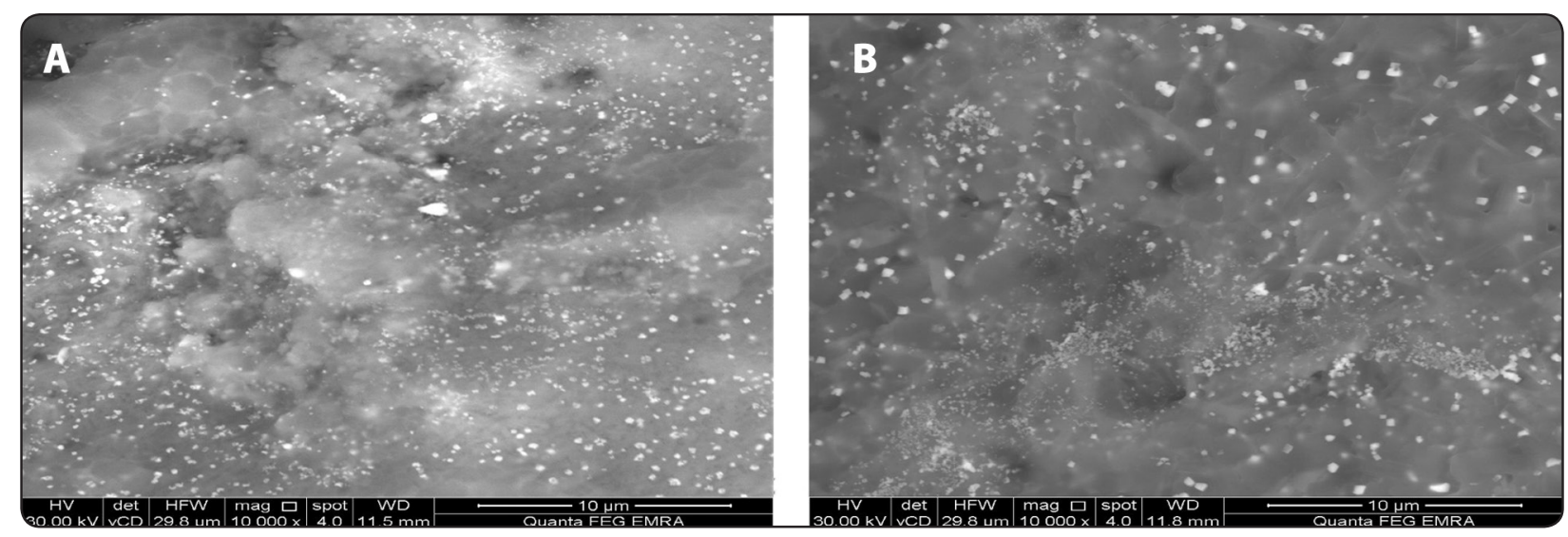

Fig. (9) Representative scanning electron microscope images (X10000) for Celtra press Where (A) represents control firing and (B) the $5^{\text {th }}$ firing cycle. 


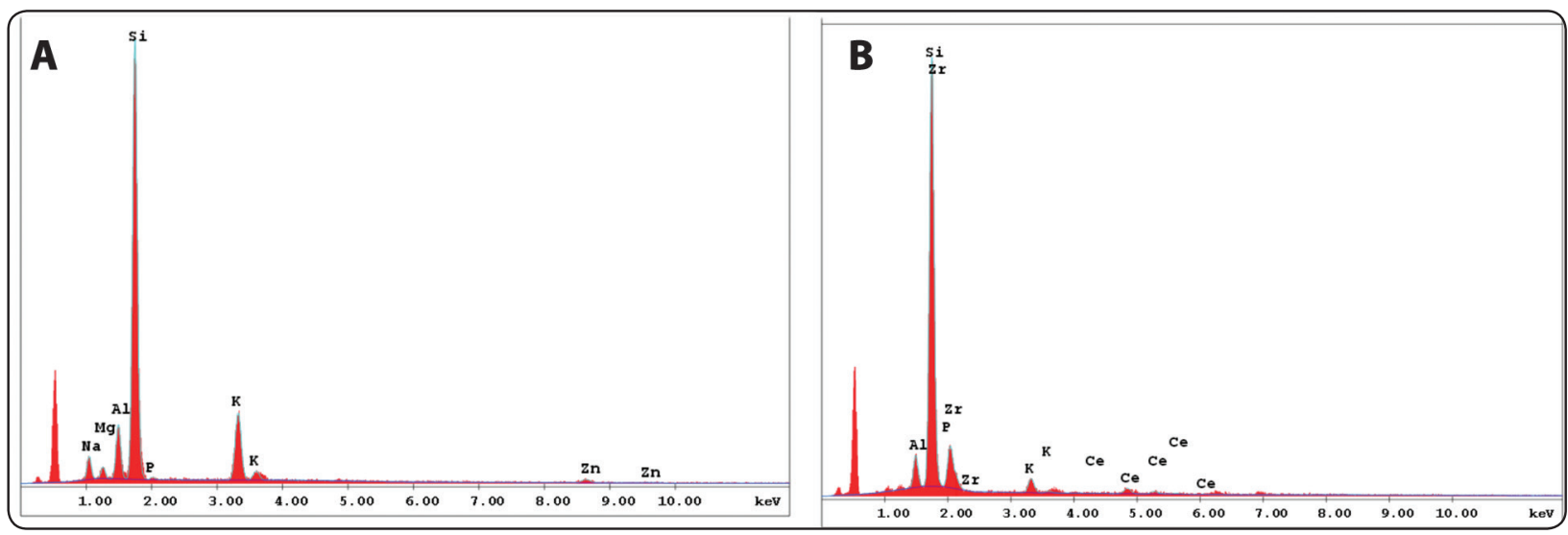

Fig. (10) EDAX for IPS e.max press (A) and Celtra press (B) for control firing group.

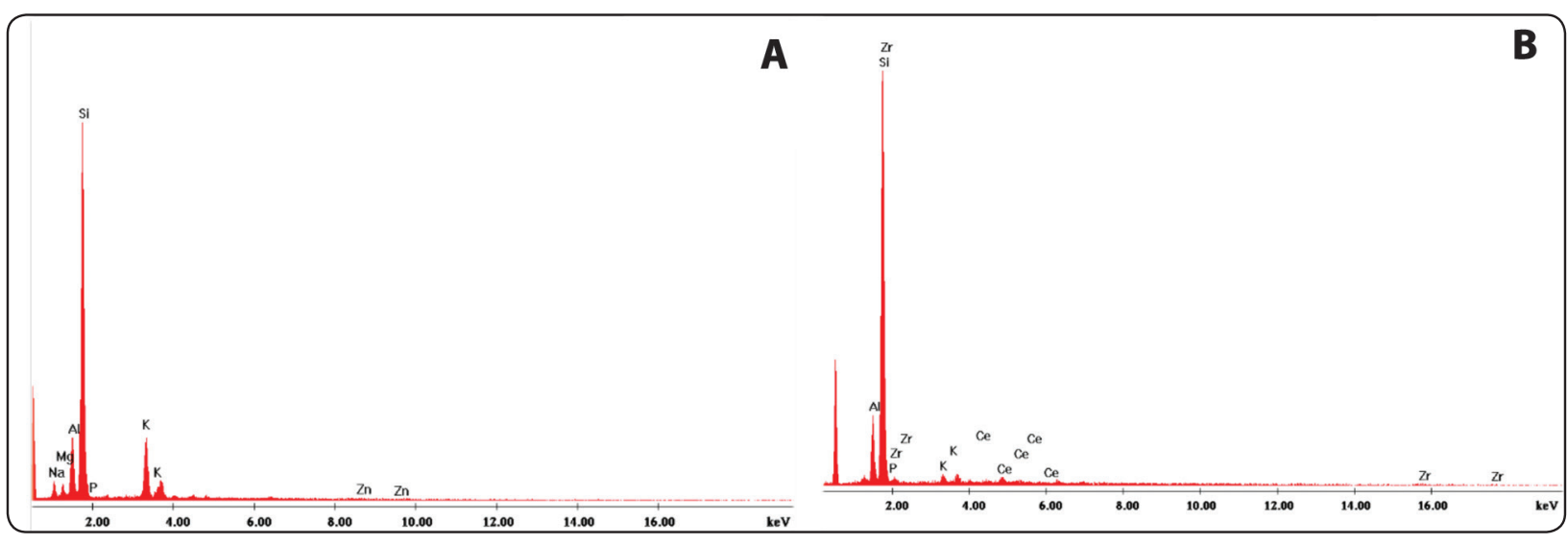

Fig. (11) EDAX for IPS e.max press (A) and Celtra press (B) for $5^{\text {th }}$ firing group.

\section{DISCUSSION}

Color stability is an important esthetic parameter for metal free all ceramic restorations ${ }^{(27)}$. The susceptability of color changes after repeated firing and its effect on microstructure has gained great interest in several studies ${ }^{(26-32)}$.

Digital color measuring devices such as colorimeters and spectrophotometers have become a popular method for measuring color differences in all ceramic restorations after processing or during clinical service ${ }^{(5,33,34)}$. Based upon the results of this invitro study, the null hypstheses are rejected.

Color measurments were done for the crowns over the underlying dentin of the prepared natural teeth without cementation in order not to involve the color of the cement as an extra variable in our study as well as simulating the clinical conditions.It is significant to state that the shade of the underlying dentin was measured for all the prepared teeth and only shade A2 was included in this study.Authors prefered to choose maxillary central incisors so that a wide flat labial surface of the ceramic crown was obtained to facilitate measurments of color $(\Delta E)$ using the probe tip of the clinically used Vita easy shade device.

In dental color science,there are two major thresholds to define the difference in color of two samples. The perceptability threshold (PT) is defined as the smallest color difference that can be perceived by $50 \%$ of the observers between two 
samples,while the acceptability threshold(AT) is defined as the smallest color difference noticed by $50 \%$ of the observers but not considered acceptable under clinical conditions ${ }^{(35)}$. Paravina et al ${ }^{(36)}$ studied these two thresholds and concluded that visual color measurements can be used to aid in aesthetic selection of dental materials and relate them to instrumental outcomes in research projects.

According to previous Studies, $\Delta \mathrm{E}$ value of 1 represents a color change perceivable by $50 \%$ of obervers under controlled conditions ${ }^{(37,38,39)}$. A $\Delta \mathrm{E}$ value of 2.72 represents a change perceivable by ordinary observers or patients ${ }^{(40)}$, however, the clinically permitted $\Delta \mathrm{E}$ value is between $\leq 3.3$ and $\Delta \mathrm{E} \leq 3.7^{(28)}$. Based on such literature, For both IPS e.max press and Celtra press, there was no statistically significant difference between mean $\Delta \mathrm{E}$ at different firing cycles except from the first to third firing cycles $(\mathrm{P}<0.5)$. Zirconia reinforced lithium disilicate subjected to repeated firing cycles had a significant color change $(\Delta \mathrm{E}$ $=4.18$ ) higher than the acceptability threshold $(\Delta \mathrm{E} \leq 3.7)$ (Table 8). Although the statistically significant color change for lithium di-silicate based ceramics after repeated firing $(\Delta \mathrm{E}=3.24)$ is perciptable but still clinically acceptable. Thus, repeated firing is not recommended for ziconia reinforced lithium di-silicate because color changes are exceeding the clinical acceptability.Our results was contradicting with Bagis and Turgut ${ }^{(41)}$ who studied the optical properties of ceramic systems for laminate veneers and they stated that there was no significance difference betwwen the $\mathrm{L}^{*}, \mathrm{a}^{*}, \mathrm{~b}^{*}$ and chroma values or the translucency of the lithium disilicate specimens fabricated through heat press or CAD /CAM technique.Firing ,pressing ,or machining procedures appear not to influence the color of these ceramic materials. The different crystalline composition may influence the optical propeties rather than the fabrication technique. The same results was stated by skyllouriotis et al ${ }^{(42)}$. Coinciding with our results, Aurelio LA et $\mathrm{al}^{(43)}$ who evaluated the effect of the extended and conventional glaze firings on optical characteristics and crystalline structure of four cermaics and they concluded that color differences produced by lithium disilicate were perciptable but still clinically acceptable, while for zirconia reinforced lithium disilicates color differences were not clinically accepted.

The color differences $\Delta$ Eobtained after repeated firing presented as a composite of changes in individual color coordinates and clear altetration in color parameters. This results might be attributed to the lower glassy conent in microstructure of both tested materials, which need compensating additives (metal oxides,coloring ions) to control optical properties like opalescence,color and opacity. These oxides tend to be unstable when the material undergoes repeated firing cycles ${ }^{(15,44)}$ resulting in increased color changes in all ceramics compared to the control group color.

The XRD and SEM data confirmed that the tested materials (lithium di-silicate glass ceramics and zirconia reinforced lithium disilicate) has a dominant crystalline phase except for lithium di-silicate for the control firing cycles as it was presented as finger print amorphous phase with no crystalline structure, so no dominant peaks were detected and the crystal amount did not change after repeated firing cycles. (Fig.4A). For the $5^{\text {th }}$ firing of lithium di-silicate ceramic material as well as control samples and $5^{\text {th }}$ firing, the results samples for zirconia reinforced lithium di-silicate revealed that a crystalline structure was noticed with highest peaks of .lithium di-silicate which was recognized to be the main crystalline phase. (Fig.5B, 5A, 5B) Dominant peaks for lithium di-silicate $\left(\mathrm{Li}_{2} \mathrm{Si}_{2} \mathrm{O}_{5}\right)$ were detected at $2 \Theta$ values of 23.75, 24.26, 24.8 and 37.5 degrees. The highest peak was at 23.75 degrees corresponding to the standard peaks for lithium disilicate, while Dominant peaks for lithium phosphate $\left(\mathrm{Li}_{3} \mathrm{PO}_{4}\right)$ were detected at $2 \Theta$ values of $22.25,24.26$, 
24.66 and 24.72 degrees. The highest peak was at 22.25 degrees corresponding to the standard peaks for lithium phosphate, the crystalline peaks appear to be more dominant for zirconia reinforced lithium disilicate especially after repeated firing protocol.

Lithium di silicate elongated crystals pressent in the glassy matrix and appeared to form interlocking pattern in some sites specially with zirconia reinforced lithium disilicate ceramics, However, the crystals were seen to be larger after the $5^{\text {th }}$ firing cycles for both materials. This was on the contrary of Aurelio LA et $\mathrm{al}^{(43)}$ who studied the effect of extended and conventional glaze firing on crack healing, residual stresses, optical properties and crystalline microstructure of two pressable ceramics. They stated that extended glaze firing did not result in any alteration in the microstructure for two pressable ceramics.

Microstructure results for this in vitro study revealed that there was a modification in the microstructure of the two pressable ceramics tested, thus the null hypothesis is rejected. This findings were very obvious with lithium disilicate ceramics which started with amorphous microstructure and ended with crystalline phase with dominant peaks after repeated firings. The absence of zirconia crystalline phase indicates that the $\mathrm{ZrO}_{2}$ remains amorphus ,dissolved and aggregated in the glassy matrix. The statement that repeated firing cycles did not trigger changes in the crystalline phase of the material shows that the firing cycles appears not to vary the microstructure established by the manufacturer $^{(45)}$. This was in agreement with Yilmaz et al (2), they stated that continous and/or high temperature firings in silicate based materials could cause pyroplastic stream, recrystallization and devitrification and as a result of these alterations, color changes could reach unacceptable limits.

Further investigations are needed to examine the effect of the repeated firings on the mechanical properties of ceramic materials and the adhesive bond strength to dental tissues.Morevere, the effect of repeated firings on the translucency of all ceramic materials required futher investigations

\section{CONCLUSIONS}

Within the limitation of this study, the following conclusions were drawn:

- Color stability is affected by repeated firing for both tested materials.

- Repeated firing is not recommended for ziconia reinforced lithium di-silicate because color changes $(\Delta \mathrm{E}=4.18)$ are exceeding the clinical acceptability.

- The color differences $\Delta \mathrm{E}$ obtained after repeated firing presented as a composite of changes in individual color coordinates and clear altetration in color parameters.

- Repeated firings might result in microstructral changes within the ceramic materials.

- Microstructure analysis through SEM, EDAX and XRD is a reliable analytical approach. .

\section{REFERENCES}

1. Molin M, Karlsson S. A clinical evaluation of the Optec inlays system. Acta. Odontol Scand. 1992; 50:227-233.

2. Yilmaz K, Gonuldas F, Ozturk. The effect of repeated firings on the color change of dental ceramics using different methods. J Adv.Prosthodont. 2014; 6:427-433.

3. Chen ZP, Xiang ZX, Song XF, Yin L. Machinability: Zirconia-reinforced lithium disilicate glass ceramic versus lithium disilicate glass ceramic. J Mech. Behav. of Biom Mater. 2020; 101:e1-e10.

4. Karaarslan ES, Bulbul M, Yildiz E, Secilmis A, Sari F, Usumez A. Effects of different polishing methods on color stability of resin composites after accelerated aging. Dent Mater J. 2013;32(1):58-67.

5. Turgut S, Bagis B. Color stability of laminate veneers: An in vitro study. J of Dent 2011; 39: 57-64.

6. Rosentritt M, Sawaljanow A, Behr M, Kolbeck C, Preis V. Effect of tooth brush abrasion and thermmechanical loading on direct and indirect veneer restorations. Clin Oral Invest 2015; 19: 53-60. 
7. Ozcelik B, Yilmaz B, Ozcan I, Kircelli. Colorimetric analysis of opaque porcelain fired to different base metal alloy used in metal ceramic restorations. J Dent 2008; 99: 193-202.

8. Yilmaz B, Karaagaclioglu L. In vitro evaluation of color replication of metal ceramic specimens using visual and instrumental color determinations. J Dent. 2011; 105: 21-27.

9. Serbena, F.C., Mathias, I., Foerster, C.E., Zanotto, E.D. Crystallization toughening of a model glass-ceramic. Acta. Mater. 2015; 86:216-228.

10. Song, X.F., Ren, H.T., Yin, L. Machinability of lithium disilicate glass ceramic in vitro dental diamond bur adjusting process. J. Mech. Behav. Biomed. Mater. 2016; 53:78-92.

11. Tang, X., Tang, C., Su, H., Luo, H., Nakamura, T., Yatani, $H$. The effects of repeated heat-pressing on the mechanical properties and microstructure of IPS e.max Press. J. Mech. Behav. Biomed. Mater.2014; 40:390-396.

12. Hallmann, L., Ulmer, P., Kern, M. Effect of microstructure on the mechanical properties of lithium disilicate glass-ceramics. J. Mech. Behav. Biomed. Mater. 2018; 82:355-370.

13. Callister WD, Rethwisch DG. Materials science andengineering: an introduction. 8th ed. São Paulo: Wiley; 2012.

14. Panzeri Pires-de-Souza FDC, Casemiro LA, Roberti Garcia LDF, Cruvinel DR. Color stability of dental ceramics submitted to artificial accelerated aging after repeated firings. J Prosthet. Dent 2009; 101:13-8.

15. Ozturk O, Uludag B, Usumez A, Sahin V, Celik G. The effect of ceramic thickness and number of firings on the color of two all-ceramic systems. J Prosthet Dent 2008; 100:99-106.

16. Fraga S, Valandro LF, Bottino MA, May LG. Hard machining glaze firing and hydrofluoric acid etching: do these procedures affect the flexural strength of a leucite glassceramic? Dent Mater 2015; 31:e131-40.

17. Barreiro M, Vivente E. Kinetics of isothermal phase transformations in a dental porcelain. J Mater Sci Mater Med1993; 4:431-6.

18. Mackert Jr JR, Sheen GW, Williams AL, Russell CM, Ergle JW. Effects of local cooling rate and processing variables on leucite in dental porcelain. Int. J Prosthodont. 2003; 16:647-52.
19. Claus H. The structure and microstructure of dental porcelain in relation to the firing conditions. Int J Prosthodont. 1989; 2:376-384.

20. Cho SH, Nagy WW, Goodman JT, Solomon E, Koike M. the effect of multiplr firings on the marginal integrity of pressable ceramic single crowns. J Prosthet Dent 2012; 107:17-23.

21. Douglas RD, Steinhauer TJ, Wee AG. Intra oral determination of the tolerance of dentists for perceptibility and acceptability of shade mismatch. J Prosthet. Dent. 2007; 97:200-208.

22. Ragain JR, Johnston WM. Color acceptance of direct dental restorative materials by human observers. Color Res. and Appl. 2000; 25:278-285.

23. Nogueira AD, Della Bona A. The effect of a coupling medium on color and translucency of CAD/CAM ceramics. J of Dent.2013; 41:e18-e23.

24. Barath VS, Faber FJ, Westland S, Niedermeier. Spectrophotometric analysis of all-ceramic materials and their interaction with luting agents and different back grounds. Adv Dent Res. 2003; 17:55-60.

25. Vichi A, Ferrari M, Davidson CL. Influence of ceramic and cement thickness on the masking of various types of opaque posts. J Prosthet Dent. 2000; 83:412-417.

26. Alghazali N, Burnside G, Moallem M, Smith P, Preston A, Jarad FD. Assessment of perceptibility and acceptability of color difference of denture teeth. J of Dent.2012; 40:e10e17.

27. Al kheraif A, Qasim S, Ramikrishnaiah R, Rehman I. Effect of different beverages on color stability and degree of conversion of nano and microhybrid composites. Dent Mater J 2013; 32(2): 326-331.

28. Kim SJ, Woo JM, Jo CW, Park JH, Kim SK, Kahm SH. Color changes of ceramic veneers following glazing with respect to their composition. J Adv Prosthodont 2019; 11:16-22.

29. Hallmann L, Ulmer P, Gerngross MD, Jetter J, Mintrone M, Lehmann F, Kern M. Properties of hot-pressed lithiumsilicate glass-ceramics. Dent Mater 2019:; 35:713-729.

30. Dittmer M, Ritzberger C, Schweiger M, Rheinberger V, Worle M, Holand W. Phase and microstructure formation and their influence on the strength of two types of glassceramics. J Non Cryst Solid 2014; 384:55-60. 
31. Li D, Guo JW, Wang XS, Zhang SF, He L. Effect of crystal size on the mechanical properties of a lithium disilicate glass-ceramics. Mater Sci and Engin A.2016; 669:332-339.

32. Gozneli R, Kazazoglu E, Ozkan Y. Flexural properties of leucite and lithium disilicate ceramic materials after repeated firings. J Dent Scien.2014; 9:144-150.

33. Patel SB, Gordan VV, Barrett AA, Chen C. The effect of surface finishing and storage solution of resin based composites. J Am Dent Assoc 2004; 135:587-594.

34. Vichi A, Ferrari M, Davidson CM. Color and opacity variations in three different resin based composite products after water aging. Dent Mater J 2004; 20: 530-534.

35. Shama G, Wu W, Dalal EN .The CIEDE2000 color difference formula: implementation noted supplementary test data, and mathematical observations. Color Res Appl.2005; 30(1):21-30.

36. Paravina RD, Ghinea R, Herrera LJ. Color difference thresholds in dentistry. J Esthet Restor Dent.2015; 27(S1):S1-S9.

37. Ryu SY, Lim JH, Cho IH. A study on the color stability of porcelain for porcelain fused to metal crown. J Korean Acad Prosthodont 2000; 38:73-84.

38. Al Ben Ali A, Kang K, Finkelman MD, Zandparsa R, Hirayama $H$. The effect of variations in translucency and background on color differences in CAD/CAM lithium disilicate glass ceramics. J Prosthodont 2014; 23:213-20.

39. Awad D, Stawarczyk B, Liebermann A, Ilie N. Translucency of esthetic dental restorative CAD/CAM materials and composite resins with respect to thickness and surface roughness. J Prosthet Dent 2015; 113:534-40.

40. Ragain JC, Johnston WM. Color acceptance of direct dental restorative materials by human observers. Color Res Appl 2000; 25:278-85.

41. Bagis B, Turgut S. Optional properties of current ceramics system for laminate veneers. J Dent.2013; 41:e24-e30.

42. Skyllouriotis AL, Yamamoto HL, Nathanson D. Masking properties of ceramics for veneer restorations. J Prosthet Dent. 2017; 118(4):517-523.

43. Aurelio IL, Dorneles LS, May LG. Extended glaze firing on ceramics for hard machining: Crack healing, residual stresses, optical and microstructural aspects. Dent Mater. 2017; 33:226-240.

44. Panzeri Pires-de-souza FDC, Casemiro LA, Roberti Garcia LDF, Cruvinel DR. Color stability of dental ceramics submitted to artificial accelerated aging after repeated firings .J Prosthet.Dent.2009;101:e8-e13.

45. Yuan K, Wang F, Gao J, Sun X, Deng Z, Wang H, Chen, J. Effect of sintering time on the microstructure, flexural strength and translucency of lithium disilicate glass-ceramics. J. Non-Cryst. Solids.2013; 362:7-13. 